\title{
Some Exploitation Properties of Wood Plastic Composites (WPC), Based on High Density Polyethylene and Timber Industry Waste
}

\author{
Janis KAJAKS $^{1}{ }^{*}$, Anita ZAGORSKA ${ }^{1}$, Artis MEŽINSKIS ${ }^{2}$ \\ ${ }^{1}$ Riga Technical University, Institute of Polymer Materials, Riga, LV-1048, P. Valdena str.3, Latvia \\ ${ }^{2}$ SIA “AM Energy”, Kekava, LV-2123, Ausekla str.4, Latvia \\ crossref http://dx.doi.org/10.5755/j01.ms.21.3.7283
}

Received 09 June 2014; accepted 25 December 2014

\begin{abstract}
In this study, the influence of wood fiber content (40, 50 and 60 wt.\%) and coupling agent concentration (3 and 5 wt.\%) on the mechanical properties of wood-plastic composites (WPCs) was investigated. Two types of plastic (high-densitypolyethylene (HDPE) and recycled high-density-polyethylene (rHDPE)) were used as polymer matrices for preparing WPC. As reinforcement, prior grinded (fiber length $<0.5 \mathrm{~mm}$ ) coniferous wood shavings were utilized. Overall trend showed, that by adding a wood fiber, flexural properties and microhardness of the composites significantly were enhanced. However, impact strength, water resistance, and fluidity of polymer melts decreased with increase in fiber content. The virgin HDPE-based composites as well as recycled HDPE-based composites, reinforced with fibers from coniferous wood, showed good mechanical properties. Based on the findings in this work, it appears that WPCs based on virgin HDPE, as well as on recycled HDPE, can be used to manufacture value-added panels. Optimal content of wood fibres were 50 - 60 wt.\%.

Keywords: recycled high-density-polyethylene, wood waste, composites, exploitation properties.
\end{abstract}

\section{INTRODUCTION}

Polymer composites reinforced with lignocelluose fiber (LCF), as an important branch in the field of composite materials, have been widely used for decades. Due to the inherent relationship between the materials and their availability, ecological, and technological effects researches are made to end up with proper material selections. Utilization of these natural fibres in innovative polymer composites, also is defined by their low cost and density, as well as practically unlimited resources with very fast ability to recover [1-3]. Polymer composites containing LCF have acceptable technological properties thus allowing to process these compositions by traditional polymer processing methods like extrusion.

One of the most perspective LCF comprising systems are wood plastics composites (WPC). Therefore, during last 20-30 years many researchers have paid attention to the studies of the materials, based on thermoplastic polymer matrices, mainly polyolefines [1, 3-7]. Materials containing LCF, also are scrap-wood-derived fillers, for example, timber industry waste. Wood waste is very cheap and timber industry produces a great amount of different types of this waste, for example, plywood production technology. Previous studies have shown [8] possibility to use wood waste for preparing wood plastic composites based on a polypropylene. Made WPC have good physicalmechanical properties (tensile, flexural and impact strength) as well as water resistance. Excellent interaction between polymer matrix and wood fibers was confirmed by SEM investigations [8]. The main goal of this study was to determine exploitation properties of the composite

\footnotetext{
* Corresponding author. Tel.:+371-67089219; fax: +371-67615765. E-mail address: kajaks@ktf.rtu.lv(J. Kajaks)
}

containing coniferous tree fiber and high-density polyethylene.

\section{EXPERIMENTAL DETAILS}

The industrial grade of virgin high-density polyethylene HMA 014 (Exxon Mobile Chemical) with $4 \mathrm{~g} / 10 \mathrm{~min}$ melt flow index as well as recycled high-density polyethylene produced by "Nordic Plast,, (Latvia) with $0.8-1.5 \mathrm{~g} / 10 \mathrm{~min}$ melt flow index were used as polymer matrices for preparing WPC. The coupling agent used was maleated polypropylene (MAPP) (Clariant International Ltd), having the trade name of Licocene PP MA-7452 with $41 \mathrm{mg} \mathrm{KOH/g}$ acid number. Pine tree shavings were ground to a fraction smaller than $0.5 \mathrm{~mm}$ by using a Retsch mill, and then dried in an oven at $105 \pm 2{ }^{\circ} \mathrm{C}$ for $24 \mathrm{~h}$ to decrease moisture content. Samples of the composites (wood fibre content (40, 50, 60 wt.\%)) were manufactured by mixing on two-roll mill $\left(T=180^{\circ} \mathrm{C}, t=12 \mathrm{~min}\right)$, cooled and granulated (average size of the chips $1-3 \mathrm{~mm}$ ). Flexural and impact strength tests were done for standard specimens (EN ISO-178 and ASTM D 256M), bars (4 X $10 \times 80 \mathrm{~mm})$ were produced by injecting moulding. Technological properties (fluidity) of the WPC melts were estimated with MFI $\left(T=190^{\circ} \mathrm{C}, P=5 \mathrm{~kg}\right.$ (rHDPE) and $P=2.13 \mathrm{~kg}$ (HDPE)) measurements (ASTM D 1238), but water resistance and swelling of materials were evaluated according to the standard ASTM D 570-88. Microhardness $(\mathrm{MH})$ of the samples were done by Vikerss $\mathrm{M}-41$ at load $200 \mathrm{~g}$.

\section{RESULTS AND DISCUSSION}

Physical-mechanical properties (flexural strength and modulus, maximum bending deformation and impact strength) of the different compositions are presented in 
Fig. 1 - Fig. 4. The results show that the flexural strengths (Fig. 1) and modulus (Fig. 2) increased with an increase in the content of wood fiber. Compositions based on virgin (Fig. 2, curve 1) high-density polyethylene matrix showed slightly higher values than based on a recycled (Fig. 2, curve 2) high-density polyethylene matrix. Furthermore, flexural strength increased up to two times (Fig. 1 dark columns) but flexural modulus increased 3.5-4 times (Fig. 2).

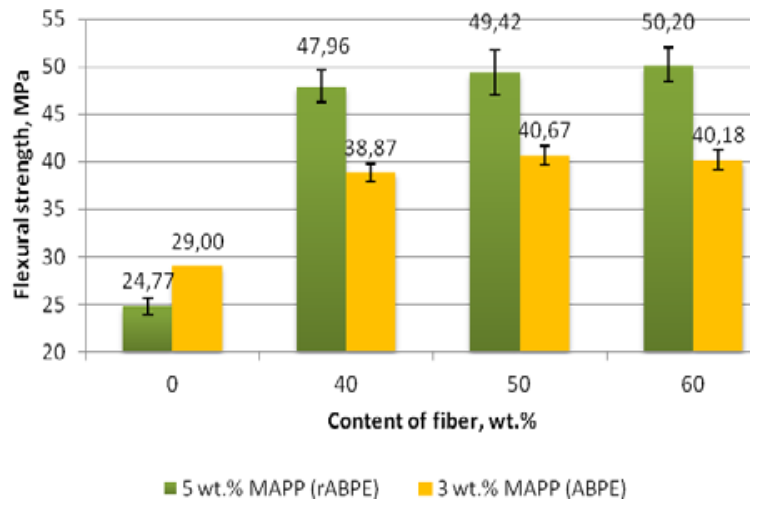

Fig. 1. Effect of wood fibre content on a flexural strength of the high-density polyethylene composites: virgin HDPE (light columns), recycled HDPE (dark columns)

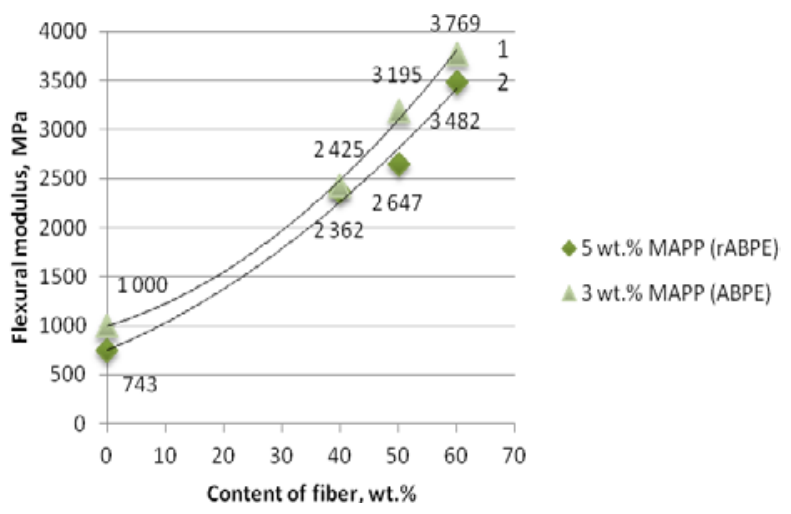

Fig. 2. Effect of wood fibre content on a flexural modulus of the high-density polyethylene composites: virgin HDPE (curve 1), recycled HDPE (curve 2)

On the contrary, deformation ability of WPC diminished with the increase of wood fibre content. This phenomenon attests decrease of the maximum of bending deformation numerical values before the break of a specimen (Fig. 3).

The highest possible deformations are only $1.29 \%$ for virgin HDPE matrix compositions and $1.79 \%$ for recycled rHDPE compositions. It means, that flexibility of WPC under influence of wood fibres can diminish up to 3-4 times (see Fig. 3, curve 2). With the addition of interfacial modifier MAPP (3-5 wt.\%) the compatibility between wood fibre and HDPE is improved, for that reason, mixing is more effective, in result, diminishes heterogeneity of WPC and improves physical and mechanical properties of materials $[4,5]$. The increase of flexural strengths, modulus and the decrease of bending deformation can be called by diminishing mobility of macromolecules of the polyethylene matrix in interfacial layers and on the surface of fibres. Actually, forms of the third phase are partially exchanged. It occurs mainly as strengthened properties. The higher is content of the filler, the bigger quantity of the third phase is in the composite.

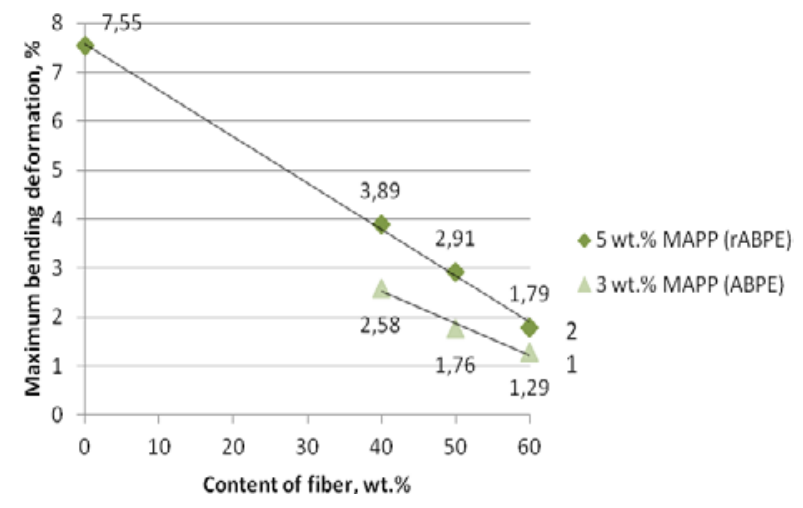

Fig. 3. Effect of wood fibre content on maximum bending deformation of the high-density polyethylene composites: virgin HDPE (curve 1), recycled HDPE (curve 2)

Impact strength (A) tests also showed decrease in numerical values with an increase of wood fibre content for both matrix composites (Fig. 4). It is caused because wood fibres are stiffer than polymer matrix. The decrease of impact strength 31.71 to $6.28 \mathrm{~kJ} / \mathrm{m}^{2}$ is significant.

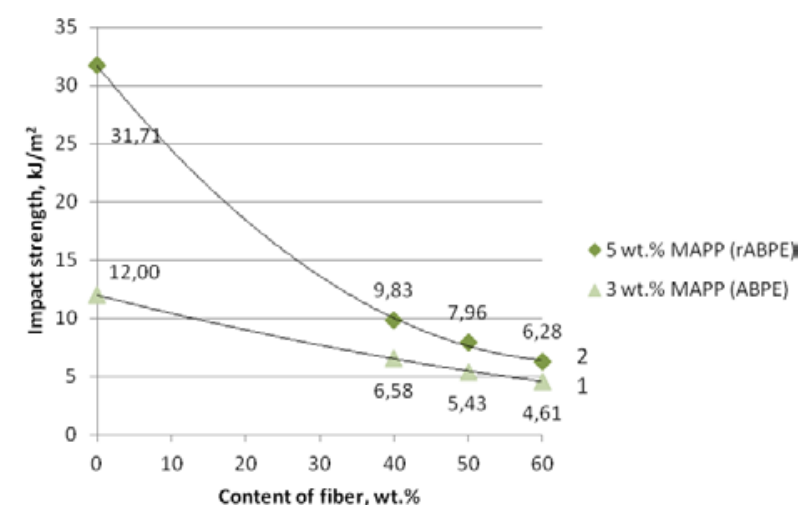

Fig. 4. Effect of wood fibre content on impact strength of the high-density polyethylene composites: virgin HDPE (curve 1), recycled HDPE (curve 2)

Simultaneously, with the studies of physicalmechanical properties, fluidity of the composite melts was also controlled. It was done by the measurements of the melt flow index (MFI). These studies showed that a significant decrease of MFI takes a place in the case of virgin HDPE: from $4.0 \mathrm{~g} / 10 \mathrm{~min}$ till $0.05 \mathrm{~g} / 10 \mathrm{~min}$ for composite with 60 wt.\% WF. Fluidity of recycled HDPE do not diminish so much: from $1.1 \mathrm{~g} / 10 \mathrm{~min}$ for pure matrix up to $0.064 \mathrm{~g} / 10 \mathrm{~min}$ for composite containing 60 wt.\% wood fibre. Nevertheless, noted values of the MFI make it possible to process such polymer composites by traditional polymer processing methods. For example, extrusion, and to produce different WPC continued profiles.

The results of microhardness tests are shown in Table 1. Microhardness is an important factor to evaluate the possibility of using materials as artificial lumber 
(wood) materials like boards, lath, and ledge and so on. From the results we can make conclusion that surface microhardedness of the samples vitally depend on fibre content in WPC. In the case of rHDPE microhardness, values increased more than 2-3 times, which confirmed the fact that wood fibres not only reinforce HDPE polymer matrix but also is making material harder.

Table 1. Results of the microhardness (MH) measurements

\begin{tabular}{|l|c|}
\hline \multicolumn{1}{|c|}{ Composite composition } & MH, MPa \\
\hline Recycled rHDPE & 69.9 \\
40 wt.\% WF+5 wt.\% MAPP+rHDPE & 113.4 \\
50 wt.\% WF+5 wt.\% MAPP+rHDPE & 124.0 \\
60 wt.\% WF+5 wt.\% MAPP+rHDPE & 152.3 \\
\hline 50 wt.\% WF+3 wt.\% MAPP+rHDPE & 122.7 \\
60 wt.\% WF+3 wt.\% MAPP+rHDPE & 141.0 \\
\hline Virgin HDPE & 64.0 \\
40 wt.\% WF+3 wt.\% MAPP+HDPE & 156.0 \\
50 wt.\% WF+3 wt.\% MAPP+HDPE & 161.4 \\
60 wt.\% WF+3 wt.\% MAPP+HDPE & 204.3 \\
\hline
\end{tabular}

Adding hygroscopic wood fibres to the thermoplastic polymer matrix causes an increase of water uptake that limits the usage of these materials in exposed environments $[7,8]$. Therefore, water resistance of WPC which is noted by water absorption measurements are very important to evaluate behaviour of WPC at elevated moisture conditions. Water absorption kinetics tests results are presented in Fig. 5. Injection of moulding results in covering of the samples surface with a layer of HDPE, which makes a barrier against the water and results in slowly of moisture. Fig. 5 shows increase of the water uptake with increasing of the content of wood fibres in composites. During $700 \mathrm{~h}$ water exposure the water amount that was absorbed increased in the cases of the both HDPE matrices. For virgin HDPE from $4.0 \%$, for composites containing 40 wt.\% WF (curve 1) up to $13.5 \%$, for system with 60 wt.\% wood fibres (curve 3), but in the case of rHDPE matrix from $2.2 \%$, for composite containing 50 wt.\% WF (curve 6) till $9.5 \%$, for material with 60 wt.\% WF (curve 8). Moreover, higher increase of absorbed water amount is observed for systems with 3 wt. $\%$ of the MAPP (curves 1-5) in comparison to rHDPE composites containing $5 \mathrm{wt} \%$ of the MAPP (curves $6-8)$.

Table 2. Results of the swelling measurements

\begin{tabular}{|c|c|c|c|c|c|c|c|c|c|}
\hline \multirow[b]{2}{*}{$\begin{array}{l}\text { Time, } \\
\text { days }\end{array}$} & \multicolumn{5}{|c|}{3 wt.\% MAPP } & \multicolumn{3}{|c|}{5 wt. $\%$ MAPP } & \multirow[b]{2}{*}{$\begin{array}{c}\text { Industrial } \\
\text { produced } \\
\text { WPC }\end{array}$} \\
\hline & $\begin{array}{c}\text { HDPE + } \\
40 \text { wt. } \% \\
\text { WF }\end{array}$ & $\begin{array}{c}\text { HDPE + } \\
50 \text { wt.\% } \\
\text { WF }\end{array}$ & $\begin{array}{c}\text { HDPE + } \\
60 \text { wt. } \% \\
\text { WF }\end{array}$ & $\begin{array}{c}\text { rHDPE + } \\
50 \text { wt. } \% \\
\text { WF }\end{array}$ & $\begin{array}{c}\text { rHDPE + } \\
60 \text { wt. } \% \\
\text { WF }\end{array}$ & $\begin{array}{c}\text { rHDPE + } \\
40 \text { wt. } \% \\
\text { WF }\end{array}$ & $\begin{array}{c}\text { rHDPE + } \\
50 \text { wt.\% } \\
\text { WF }\end{array}$ & $\begin{array}{c}\text { rHDPE + } \\
60 \text { wt. } \% \\
\text { WF }\end{array}$ & \\
\hline \multicolumn{10}{|l|}{ Width: } \\
\hline 0 & 0.0 & 0.0 & 0.0 & 0.0 & 0.0 & 0.0 & 0.0 & 0.0 & 0.0 \\
\hline 2 & 0.1 & 0.16 & 0.26 & 0.10 & 0.29 & 0.13 & 0.16 & 0.39 & 0.65 \\
\hline 10 & 0.1 & 0.52 & 0.85 & 0.13 & 0.42 & 0.16 & 0.33 & 0.62 & 1.39 \\
\hline 29 & 0.1 & 0.59 & 0.85 & 0.16 & 0.85 & 0.20 & 0.33 & 0.94 & 1.62 \\
\hline \multicolumn{10}{|c|}{ Thickness: } \\
\hline 0 & 0.00 & 0.00 & 0.00 & 0.00 & 0.00 & 0.00 & 0.00 & 0.00 & 0.00 \\
\hline 29 & 0.01 & 0.05 & 0.16 & 0.03 & 0.06 & 0.01 & 0.05 & 0.16 & 0.49 \\
\hline
\end{tabular}

Sufficiently high water resistance show specimens that were made from industrial produced WPC board s (see Fig. 5, curve 9). The total absorbed water amount after 30 days of water exposure reached $10.5 \%$, that is rather high for WPC materials. Out of WPC materials that we investigated in our research, the best water resistance demonstrated system that consist of rHDPE + 40 wt.\% WF + 5 wt.\% MAPP (2.6 \%).

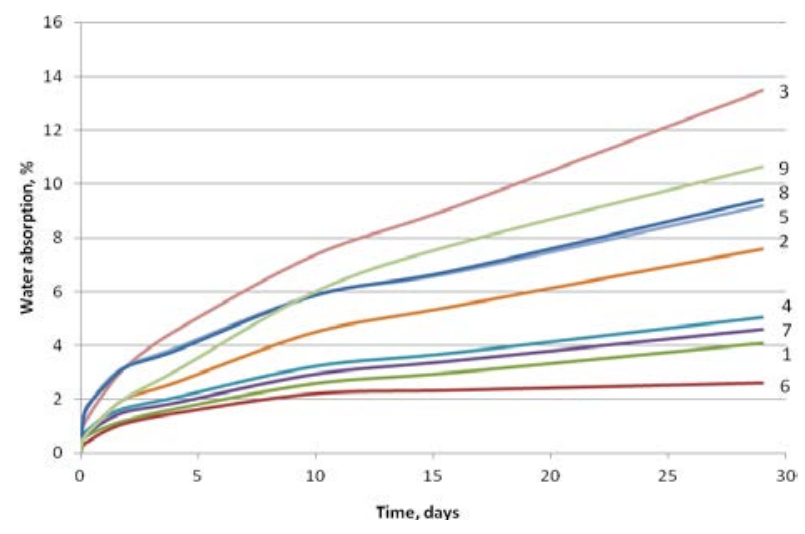

Fig. 5. Water absorption kinetics of high density polyethylene composites:

$1-\mathrm{HDPE}+40$ wt.\%WF,

$3-\mathrm{HDPE}+60 \mathrm{wt} . \% \mathrm{WF}$,

5 -rHDPE + 60 wt. $\% W F$,

$2-\mathrm{HDPE}+50$ wt.\%WF, 4-rHDPE + 50 wt. $\%$ WF, 7-rHDPE + 50 wt. $\%$ WF, $\quad 8-$ rHDPE +60 wt $\%$ WF Content of the MAPP $3 \mathrm{wt} . \%$ (curves $1-5$ ), and $5 \mathrm{wt} \%$ (curves 6-8), 9-industrial produced high density polyethylene WPC.

Swelling experiments gave encouraging results (see Table 2). Swelling measurements showed, that actually all investigated WPC materials swell insignificant under the influence of water. Thickness and width sizes of utilized samples (standard bars) changed very little. After 30 days of water influence width of the samples changed slightly and fluctuated in limits in a range of 0.1 up to $0.85 \%$ for systems based on virgin HDPE (3 wt.\% MAPP) and from 0.20 till $0.94 \%$ for systems based on rHDPE (5 wt.\% MAPP). The WF content has a minimal effect on swelling results. Thickness change in the samples of all composites is negligible (less than $0.16 \%$ ). On the contrary, industrial samples swell more $(0.49 \%$ in thickness and $1.62 \%$ in width). 


\section{CONCLUSIONS}

1. Presented studies showed that, at first, reinforcing HDPE and rHDPE matrices with wood fibre (length $<0.5 \mathrm{~mm}$ ) considerably improve physical and mechanical properties of all composites. Flexural strength increased 1.5-2 times, flexural modulus increased up to 3.5-4 times with increasing of the content of wood fibres in the composites. On the contrary, deformation ability of composites decreased 2.5-4 times.

2. The microhardness of WPC increased 2-3 times with increasing of wood fibre content, but strength of the impact of the WPC decreased 2.5-5 times.

3. Fibre content is the major factor affecting water absorption of composites, as it enhances matrix porosity by creating more moisture path into the matrices. The water amount that was absorbed by the most suitable compositions after 30 days is in a range between $2.2-4 \%$. The compositions show a very low level of swelling.

4. The coupling agent significantly improved the properties of all the composites, and results indicated better interaction of the wood fibre with the polymer matrix.

5. The recycled HDPE-based composites had similar physical and mechanical properties than that of virgin HDPE-based composites, but no significant differences were found between these two types of composites. Thus, it can be concluded that composites from recycled wood fibre and plastics have the potential to serve as a durable and environmentally friendly products.

\section{Acknowledgments}

The authors thank the SIA “AM Energy” for financial support.

\section{REFERENCES}

1. Nwabunma, D., Kun, T. Polyolefin composites, 3M Company,Wiley-Interfacescience A.John Wiley and Sons INC Publications 2007: pp. 3-82, 87-123, 150-201.

2. Saravana, Bavan, D., Mohan, Kumar, G. C. Potentional Use of Natural Fiber Composite Materials in India Journal of Reinforced Plastics and Composites 29 (24) 2010: pp. $3600-3613$.

3. Chaharmahali, M., $\quad$ Mirbagheri, J., $\quad$ Tajvidi, M., Najafi, S. K. Mechanical and Physical properties of wood plastic composite panels Journal of Reinforced Plastics and Composites 29 (2) 2010: pp. 310-319. http://dx.doi.org/10.1177/0731684408093877

4. Sain, M., Suhara, P., Law, S. Interface Modification and Mechanical Properties of Natural Fiber-polyolefin Composite Products Journal of Reinforced Plastics and Composites 24 (2) 2005: pp.121-130.

5. Yali, Li. Effect of Coupling Agent Concentration, Fiber Content, and Size on Mechanical Properties of Wood/HDPE Composites International Journal of Polymeric Biomaterials 61 2012: pp. 882-890.

6. Adhikary, K. B., Park, C. B., Islam, M. R., Rivzi, G. M. Effects of Lubricant Content on Extrusion Processing and Mechanical Properties of Wood Flour-high Density Polyethylene Composites Journal of Thermoplastic Composite Materials 24 (2) 2011: pp. 155-171.

7. Kaboorani, A., Eglund, K. R. Water Sorption and Mechanical Performance of Preheated Wood/thermoplastic Composites Journal of Composite Materials 45 (13) 2010: pp. $1423-1433$. http://dx.doi.org/10.1177/0021998310382317

8. Kajaks, J., Kalnins, K., Uzulis, S., Matvejs, J. Physical and Mechanical Properties of Composites Based on Polypropylene and Timber Industry Waste Central European Journal of Engineering 4 (4) 2014: pp. 385-390. 